\title{
Reflets
}

Revue ontaroise d'intervention sociale et communautaire

\section{Vous avez dit reconnaissance des acquis?}

\section{Marie-France Gosselin et Margot Cardinal}

Volume 3, numéro 2, automne 1997

Visibles et Partenaires : Pratiques et recherches féministes

URI : https://id.erudit.org/iderudit/026187ar

DOI : https://doi.org/10.7202/026187ar

Aller au sommaire du numéro

Éditeur(s)

Reflets : Revue ontaroise d'intervention sociale et communautaire

ISSN

1203-4576 (imprimé)

1712-8498 (numérique)

Découvrir la revue

Citer cet article

Gosselin, M.-F. \& Cardinal, M. (1997). Vous avez dit reconnaissance des acquis? Reflets, 3(2), 260-268. https://doi.org/10.7202/026187ar

Tous droits réservés (C) Reflets : Revue ontaroise d'intervention sociale et communautaire, 1997
Ce document est protégé par la loi sur le droit d'auteur. L'utilisation des services d’Érudit (y compris la reproduction) est assujettie à sa politique d'utilisation que vous pouvez consulter en ligne.

https://apropos.erudit.org/fr/usagers/politique-dutilisation/ 


\section{Vous avec dit reconnaissance des acquis?}

Marie-France Gosselin, directrice générale, Réseau national action éducation femmes (RNAÉF)

Margot Cardinal, présidente, RNAÉF

Blanche Paradis, Coopérative Convergence

\section{Introduction}

L'apprentissage est sans limites... soit, mais qu'en est-il de la reconnaissance de l'apprentissage? Qu'en est-il de cet apprentissage issu des expériences du cadre scolaire ou du quotidien? Qu'en est-il des obstacles rencontrés par les femmes francophones lors du processus d'évaluation et de reconnaissance de leurs acquis? Qu'en est-il des ressources et des programmes en reconnaissance des acquis offerts par les établissements d'enseignement?Voilà autant de questions que se sont posées les membres du Réseau national action éducation femmes (RNAÉF) et autant de réponses que devra lui apporter une recherche sur le sujet.

\section{Action du Réseau national action éducation femmes}

Créé en 1983, le RNAÉF est un regroupement national d'organismes et de membres dont le mandat est de privilégier l'éducation sous toutes ses formes pour améliorer la condition 
de vie des femmes francophones. Dès 1987, le RNAÉF avait déterminé trois champs précis d'intervention: une recherche pancanadienne visant à établir un profil de la femme francophone et de l'éducation au Canada, le dossier d'alphabétisation pour les femmes francophones et le développement d'un programme de reconnaissance des acquis. Une recherche visant à établir la place des femmes francophones et la reconnaissance des acquis, une étude exploratoire La reconnaissance des acquis scolaires et expérientiels des femmes: une alternative concrète ainsi qu'un colloque national sur la reconnaissance des acquis, tenu en 1988 à l'Université de Moncton, ont clairement démontré l'absence de politiques de reconnaissance des acquis et d'outils de mesure de ces acquis dans les établissements d'enseignement postsecondaire canadiens.

Suite au colloque de Moncton, le RNAÉF a choisi l'information et la sensibilisation comme pistes d'action. En plus de souhaiter ardemment que les femmes soient mieux renseignées, le RNAÉF souhaitait sensibiliser les établissements d'enseignement aux possibilités de reconnaitre les acquis de leur clientèle étudiante. Le colloque avait d'ailleurs clairement établi que la reconnaissance des acquis n'était pas qu'une affaire de femmes mais bien un projet de société en devenir.

\section{Reconnaissance des acquis}

Dix ans plus tard, le RNAÉF retrouve un deuxième souffle et entreprend de plus belle une croisade pour une reconnaissance de la reconnaissance des acquis. Si la reconnaissance des acquis continue d'être son cheval de bataille, c'est qu'il est fort conscient que le concept d'éducation tout au long de la vie, tel que préconisé par la Commission internationale sur l'éducation pour le XXI ${ }^{\mathrm{e}}$ siècle, présidée par Jacques Delors ${ }^{1}$, ne peut avoir une place centrale dans la dynamique sociale à moins qu'un véritable processus d'évaluation et de reconnaissance des acquis extrascolaires soit instauré dans les établissements d'enseignement et dans les entreprises. Cette reconnaissance, qui se fait jour au cœur des 
transformations en éducation, est d'autant plus importante aux femmes francophones qu'elle représente le moyen par excellence de les inciter à justement accorder une place de choix à une éducation tout au long de leur vie. Ainsi pourront-elles mieux s'adapter aux mutations qui, sans doute, surgiront autant dans leur vie professionnelle que privée.

Définie par la Commission canadienne de mise en valeur de la main-d'œuvre ${ }^{2}$ comme un processus qui permet de déterminer, d'évaluer puis de reconnaitre ce qu'une personne sait et peut faire, la reconnaissance des acquis demeure encore aujourd'hui un processus menaçant parce qu'elle est méconnue. Même si les établissements d'enseignement pratiquent traditionnellement certaines formes de reconnaissance - que l'on pense aux doctorats honorifiques octroyés par les universités pour reconnaitre l'apport exceptionnel de certaines personnes à leur société, ou encore aux admissions de certaines personnes à des programmes d'études collégiales sur la base de leur formation jugée équivalente à la formation initiale qui prévaut - il n'en demeure pas moins qu'à quelques exceptions près, elles hésitent longuement à intégrer la reconnaissance des acquis extrascolaires dans les programmes d'études, à sanctionner ces acquis et à les créditer. Le RNAÉF a pourtant espoir que dans un avenir prochain, la grande majorité des établissements d'enseignement seront en mesure de se tracer une politique officielle de reconnaissance des acquis, de la propager et surtout d'y adhérer.

Les établissements d'enseignement qui désirent accorder une place significative à la reconnaissance des acquis extrascolaires dans les programmes d'études ont certes des apprentissages à faire. Selon Marielle Préfontaine de l'Université de Moncton, université souvent citée pour sa position d'avant-garde en reconnaissance des acquis, ces apprentissages touchent chacune des trois dimensions du concept de la reconnaissance des acquis: la dimension méthodologique, outils et instruments d'évaluation; la dimension organisationnelle, rôles et rapports entre les personnes concernées; la dimension philosophique, vision de la maison d'enseignement et de ses membres. Figure de proue du mouvement vers une reconnaissance des acquis extrascolaires, Madame Préfontaine, lors d'une conférence prononcée dans le cadre du Forum sur la 
reconnaissance des acquis tenu à Moncton en novembre 1996, précisait que contrairement aux décisions de financement qui sont, pour la plupart, entre les mains des gouvernements, celles touchant la reconnaissance des acquis sont entre les mains des gestionnaires des établissements d'enseignement. «La mise en visibilité de la reconnaissance des acquis extrascolaires est une décision intrapreneuriale», disait-elle.

D'après le RNAÉF, une reconnaissance des acquis mise en exergue dans le processus éducatif exige une réflexion autour de nouveaux modèles d'éducation plus respectueux de la nature et des temps de la personne. Pour certains établissements d'enseignement, la réflexion s'avère angoissante puisqu'elle suppose de faire fi de leur chasse gardée des savoirs disciplinaires qui conduisent aux diplômes pour reconnaître des résultats d'apprentissage issus d'une symbiose de savoirs: savoir-être, savoir-faire et savoirdisciplinaire. La réflexion est d'autant plus urgente que la société de l'information qui se développe au rythme de l'éclair multiplie les possibilités d'accès aux savoirs et aux compétences.

Alors que se poursuit cette réflexion, le RNAÉF s'emploie à développer des mécanismes aptes à faire ressortir la pertinence de tous les apprentissages issus des expériences extrascolaires et, plus particulièrement, celles des femmes francophones. Ainsi a-t-il entrepris de se pencher sur l'expérience des femmes qui ont vécu une démarche de reconnaissance des acquis pour cerner les principaux obstacles qu'elles ont rencontrés tout au long du processus. Étant donné l'ampleur du sujet et de l'avis des membres d'un comité consultatif représentant les secteurs universitaire, collégial et communautaire, le RNAÉF a préféré restreindre le champ de la recherche aux expériences vécues par des femmes qui vivent en milieu minoritaire francophone et qui désirent poursuivre des études postsecondaires.

\section{Recherche}

Mandatées par le RNAÉF pour mener cette recherche sur Les 
obstacles à la reconnaissance des acquis, les chercheures ont basé leur travail sur le concept assez largement répandu qui définit la reconnaissance des acquis comme étant de faire la preuve des connaissances acquises suite à des expériences de travail rémunérées ou non, à des occupations personnelles ou familiales ou à toute autre activité ayant contribué à une formation personnelle.

Pour ce faire, les chercheures ont bâti un questionnaire qui reprenait les principales étapes d'un processus de reconnaissance des acquis. À chacune des étapes, elles ont identifié deux ou trois obstacles potentiels. Par la suite, elles ont contacté des femmes ayant vécu le processus grâce à certaines membres du RNAÉF particulièrement actives dans ce dossier. Certaines institutions d'enseignement ont également accepté de les mettre en contact avec des femmes ayant effectué le processus par l'intermédiaire de leur service. Finalement, en entrevue téléphonique, elles ont échangé avec ces femmes sur leur expérience en reconnaissance des acquis. Jusqu'à présent, elles ont discuté avec douze femmes des Maritimes, de l'Ontario et de l'Ouest canadien. Leur travail est loin d'être terminé. Cependant, elles peuvent déjà déterminer certains obstacles qu'elles se permettront de nommer et de commenter dans les pages qui suivent.

\section{Principaux obstacles rencontrés par les femmes face à la reconnaissance des acquis}

Le plus grand obstacle rencontré par les femmes, celui que la plupart des femmes ont identifié, a été celui d'établir leur portfolio. Ce portfolio est le dossier d'évaluation, c'est-à-dire l'ensemble des documents (lettres, descriptions de tâches, rapports, documents audio-visuels, etc.) qui font la preuve des connaissances expérientielles acquises par la candidate. C'est aussi ce dossier qui fait le lien entre les connaissances acquises et les cours donnés par un établissement d'enseignement qui correspondent le mieux à ces apprentissages. 
Quelques-unes des femmes interrogées ont fait ce travail dans le cadre d'un cours intitulé Connaissance de soi et reconnaissance des acquis expérientiels, supervisé par Marthe Sansregret et offert par l'Université Laurentienne. La plupart des femmes que nous avons interviewées ont d'ailleurs utilisé ce modèle de portfolio (Sansregret, 1988). Elles ont trouvé que c'était un outil assez facile à utiliser mais pas toujours pertinent. Les principales critiques portaient sur le fait que l'outil est très centré sur les détails et qu'en même temps il est trop exhaustif et ne met pas suffisamment le focus sur les apprentissages les plus importants pour le domaine d'études qu'elles ont choisi. Plusieurs ont suggéré une forme abrégée ou simplifiée du portfolio qui traitait plus spécifiquement de leur champ d'études. Certaines ont dit avoir adopté le portfolio à leurs besoins; d'autres ont dit avoir créé un modèle de portfolio. Cependant, toutes ont souligné l'importance d'un outil de ce genre.Voilà pour ce qui est de l'outil lui-même.

Les femmes ont également souligné à quel point un processus de reconnaissance des acquis est difficile à faire parce que c'est une sorte de bilan de vie. Il existe donc une difficulté importante, de type émotif, pour une femme qui doit effectuer un retour en arrière pour rédiger son portfolio. Elle doit alors confronter diverses expériences de vie, pas toujours heureuses, parfois même encore douloureuses. Certaines se retrouvent aussi devant des choix éthiques importants. Par exemple, une des femmes expliquait qu'elle avait appris énormément sur bien des plans dans une relation abusive avec son ex-conjoint. Par contre, elle a refusé de faire valoir tous ces acquis parce qu'ils font partie de sa vie personnelle et qu'elle trouvait indécent d'étaler sa vie intime pour obtenir des crédits. Plusieurs ont exprimé le fait que faire son portfolio, c'est comme faire une thérapie. Et toutes n'étaient pas prêtes à entreprendre une telle démarche.

Un autre obstacle se situe au niveau du peu de reconnaissance de la reconnaissance des acquis. Ce peu de reconnaissance se manifeste de diverses façons. Ainsi, les femmes elles-mêmes ne connaissent pas le terme, ni ce qu'il signifie. Pour elles, cette expression de reconnaissance des acquis n'a pas de signification, ne se réfere à aucun terme connu; elles ont donc besoin de se 
faire expliquer ce que cela signifie. Souvent, elles ont appris d'une collègue qu'elles peuvent avoir accès à cet outil, et en retour elles se font un plaisir de la faire connaitre aux autres. Le bouche à oreille est encore, semble-t-il, le moyen par lequel la plupart des femmes apprennent l'existence de la reconnaissance des acquis.

Certaines femmes ont également dû confronter un milieu hostile qui ne reconnaît pas la validité des connaissances acquises par expérience. Parfois, même si le concept est reconnu dans l'établissement d'enseignement, certaines personnes (membres du personnel enseignant) ou certaines instances (département ou faculté) n'appliquent pas les politiques de l'institution car elles n'y croient pas. Ainsi, une femme a dû se plaindre au sénat académique de son institution car la faculté où elle désirait faire reconnaitre ses connaissances hésitait à le faire. En effet, cette reconnaissance lui donnait droit de s'inscrire à la maîtrise et la faculté soutenait que des connaissances expérientielles n'étaient pas suffisantes pour y accéder.

Nous avons pu identifier un troisième obstacle en ce qui concerne la reconnaissance des acquis: la somme de travail nécessaire pour démontrer l'acquisition des connaissances expérientielles. En effet, plusieurs femmes ont soulevé le fait que la somme de travail exigée pour faire reconnaitre leurs acquis était souvent la même que si elles s'étaient inscrites au cours en question et l'avaient suivi en entier. Elles en arrivaient à la conclusion que faire une démarche de reconnaissance des acquis pour trois ou six crédits n'allège pas vraiment la somme de travail. De plus, il est pertinent de se demander de quelle reconnaissance il s'agit puisque l'on ne suit pas un cours mais que l'on doit effectuer autant de travail que si on en suivait un. Avant d'entreprendre une démarche de reconnaissance des acquis, il est donc pertinent de vérifier le nombre de crédits qu'il est possible d'aller chercher tout en sachant que le processus exigera la même somme de travail que l'on consacrerait normalement pour accumuler environ six crédits.

Quelques autres obstacles ont aussi été identifiés par les femmes. C'est ainsi que certaines ont souligné la lenteur du processus, tandis que d'autres ont trouvé le processus coûteux (on leur 
demande de payer les frais d'inscription au cours qu'elles veulent faire reconnaître en plus de payer un montant d'argent supplémentaire pour les frais administratifs du processus). Finalement, plusieurs ont dit avoir vécu beaucoup de stress au cours du processus.

\section{Conclusion}

Lorsque le travail de recherche sera terminé, le RNAÉF se propose de créer un répertoire électronique des ressources et des programmes existant en reconnaissance des acquis. Ce répertoire, qui sera disponible sur inforoute, aura une double fonction: d'abord de permettre aux femmes d'apprivoiser les nouvelles technologies de communication et ensuite de maximiser leurs possibilités d'accès aux programmes et services offerts en reconnaissance des acquis, et ce, d'un océan à l'autre.

À l'aube d'un XXI' siècle qui promet d'être un champ d'action fertile à la reconnaissance des acquis extrascolaires, le RNAÉF espère que ses initiatives pourront contribuer de façon significative à accroître l'égalité des chances des femmes francophones tout en assurant une meilleure diffusion du savoir. Vous aviez dit: «La reconnaissance des acquis?» Puissiez-vous un jour dire: la reconnaissance des acquis, c'était une question d'équité!

\section{Bibliographie}

COMMISSION CANADIENNE DE MISE EN VALEUR DE LA MAIN D'CEUVRE (1997). Évaluation et reconnaissance des acquis, Ottawa, Commission canadienne de mise en valeur de la main d'œuvre.

RAPPORT À L'UNESCO DE LA COMMISSION INTERNATIONALE SUR L'ÉDUCATION POUR LE XXI ${ }^{\mathrm{E}}$ SIÈCLE (1996). L'éducation: un trésor est caché dedans, Paris, Éditions Odile Jacob.

RÉSEAU NATIONAL ACTION ÉDUCATION FEMMES (1986). Étude exploratoire. La reconnaissance des acquis scolaires et expérientiels des femmes: une alternative concrète à proposer, Ottawa RNAÉF. 
RÉSEAU NATIONAL ACTION ÉDUCATION FEMMES (1988). Les actes du colloque. La reconnaissance des acquis, Ottawa, RNAÉF.

RÉSEAU NATIONAL ACTION ÉDUCATION FEMMES (en cours). Les obstacles à la reconnaissance des acquis, Ottawa, RNAÉF.

SANSREGRET, Marthe (1988). Reconnaissance des acquis, Montréal, Éditions Hurtubise HMH.

\section{Notes}

1. Voir le Rapport de la Commission internationale sur l'éducation pour le XXI ${ }^{\mathrm{e}}$ siècle (1996). Rapport à l'UNESCO.

2. Voir le document de la Commission canadienne de mise en valeur de la main d'oeuvre (1997). 